\title{
Deriving formulations for forecasting the ultimate strength of locally dented ring-stiffened cylinders under combined axial compression and radial pressure loads
}

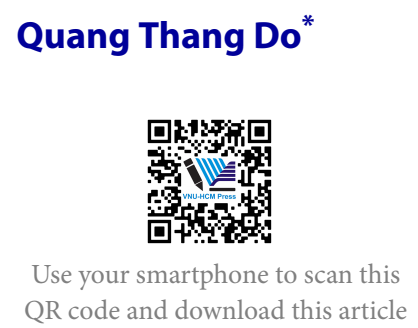

Department of Naval Architecture, Nha Trang University, Nha Trang, Vietnam

\section{Correspondence}

Quang Thang Do, Department of Naval Architecture, Nha Trang University, Nha Trang, Vietnam

Email: thangdq@ntu.edu.vn

History

- Received: 2020-06-23

- Accepted: 2020-08-19

- Published: 2020-09-02

DOI : 10.32508/stdj.v23i3.2412

\section{Check for updates}

\section{Copyright}

(.) VNU-HCM Press. This is an openaccess article distributed under the terms of the Creative Commons Attribution 4.0 International license.

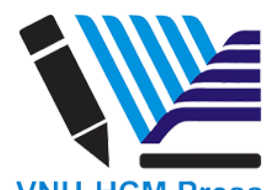

\begin{abstract}
Introduction: This paper focuses on the derived equations to evaluate the ultimate strength of ring-stiffened cylinders with local denting damage under combined loadings. The damage generation scenarios in this research are representing the collision accidents of offshore stiffened cylinders with supply ships. Methods: Numerical analysis of structures are performed using Abaqus software after validation against the experiments from the authors. The responses from seventeen cylinder specimens are analyzed to develop the numerical methods. Results: Good accuracy results were achieved when comparing the test results and the simulation results. Parametric studies are then performed on design examples of ring-stiffened cylinders when considering both intact and damaged conditions for assessing the reduction factor. Then, the novel simple design equations to assess the residual strength of ring-stiffened cylinders after ship collision are derived based on the regression analysis. These equations have good accuracy with mean value $X_{m}$ (Uncertainty modeling factor) around 1.0 and together with COV (Coefficient of Variation) lower than $5.3 \%$. Conclusion: The accuracy and reliability of the derived equations are validated by comparing it with the existing test data in open access. It is concluded that the proposed equations have high accuracy and reliability, and convenient application for the purpose of checking the residual strength of dented offshore cylinder under ship collisions.
\end{abstract}

Key words: damaged ring-stiffened cylinder, residual strength formulation, collision, axial compression, radial pressure

\section{INTRODUCTION}

Steel ring-stiffened cylinders have been widely implemented for floating offshore structures such as semisubmersibles, tension legs of platforms, submarines, and main legs of the offshore wind turbine. During operations, these structures may be potentially damaged causing ship collisions or floating objects. Collisions between ships and offshore structures are unavoidable during their service. Moreover, the major colliding structures may lead to catastrophic consequences such as endanger human life, environmental pollution, and financial losses. Obviously, the offshore stiffened cylinders should be designed with enough strength the strength enough, and safety against potential collisions. The key concern is to assess the ultimate residual strength of the structural system after collisions, and make sure that they are acceptable for safety operation. Therefore, the residual strength assessment of these structures has crucial importance for decision-making to allow the structural system operation or a stop of operation.

There are many authors providing the test results on the ultimate strength of an intact cylinder under various loadings such as external hydrostatic pressure $^{1-4}$, and combined loadings of radial pressure and axial compression/tension ${ }^{5,6}$. It is clear that during the cold bending and welding of fabricated processes, the stiffened cylinders are exposed to residual stresses. Many researchers ${ }^{7-11}$ have reported the effect of residual stresses on the ultimate strength of these structures under various loadings. Furthermore, there are also many equations that have high accuracy and reliability provided in $\mathrm{BSI}^{12}, \mathrm{GL}^{13}$, and $\mathrm{ABS}^{14}$ rules.

However, there are only several researchers who presented the residual strength of these structures after the collision. Harding and Onoufriou ${ }^{15}$ conducted the quasi-static denting test on ring-stiffened cylinders, and these models were subsequently tested under axial compression. Walker \& $\mathrm{McCall}^{16}$ reported the test results of dented ring-stiffened cylinders under combined external hydrostatic pressure and axial compressive loadings. However, they generated the damages on models by quasi-static denting. It is quite different from actual cases because most ships and offshore structural collisions in the actual ocean have oc- 
curred under dynamic collisions. Recently, Cerik ${ }^{17}$ provided the numerical simulations of the damaged ring-stiffened cylinder under compressive loadings. The models have induced the damages by dynamic impact machines. Furthermore, Do et al. ${ }^{18}$ and Cho et al. ${ }^{19}$ conducted four large-scaled fabricated ringstiffened cylinders under the dynamic mass impact, and all specimens were subsequently tested under hydrostatic pressure for assessing the reduction in ultimate strength.

Nowadays, nonlinear finite element methods (NFEM) are great tools to forecast ship and offshore cylinder structural collisions. It is also the convenience and economic efficiency to perform the full scale of reality structures where all boundary conditions and material properties can be included ${ }^{20-22}$. Therefore, the best way to evaluate the ultimate strength after collisions between ship and offshore cylinders is carefully performed the NFEM.

To the best authors' knowledge, until now, there were no formula or design codes which provided reliable equations to forecast the residual strength of ringstiffened cylinders after a collision under combined loadings. Thus, it is greatly necessary to derive the novel equations to evaluate the residual strength of these structures under combined loadings. This research's goal is to insert in that gap.

Based on this background, the main goal of this research is to develop the NFEM to forecast the residual strength of ring-stiffened cylinders after collisions under combined loadings. Then, closed-form formulas are derived to evaluate the residual strength of these structures under combined loadings. These equations are convenient to use as well as high accuracy results when comparing with the existing test data.

\section{FINITE ELEMENT MODELLING}

\section{Description of test data}

Seventeen small fabricated scale ring-stiffened cylinders were analyzed. There were eight models reported by Harding and Onoufriou ${ }^{15}$ in the UK. In these experiments, the models were artificially dented and subsequently loaded axially to determine their residual load-carrying capacity. Internal transducers measured the relative displacement of the two endplates in contact with the model so that the end-shortening can be inferred. The load was applied in small increments, and the step size was reduced as the collapse was approached to ensure that nonlinearity in the response and the peak load was accurately measured. The depth of the dent in each model was different. Six models from R1 to R6 were provided by Walker \& McCall ${ }^{16}$ at the University of Surrey, UK. They investigated the ultimate residual strength of a quasi-denting ring-stiffened cylinder under combined radial pressure and axial compression. Other models, namely RS-I, RS-C-1, 2, 3, and RS-C-4 were presented by author $^{18,19}$ at the University of Ulsan, Korea. For these models, the damaged generations were provided using dynamic impact tests. Then, all models were subsequently performed under hydrostatic pressure. The detail of the scantling and material properties of each model can be found in Table 1 and Table 2 .

\section{Finite element modeling}

The processes of collision simulations and collapse simulations under axial compression and radial pressure were carried out using Abaqus dynamic explicit and static Riks approaches. All structures were modeled by shell element S4R. These element types are hourglass control and decreased the time integration. The striker was modeled as a rigid body with a R3D4 element type. The contact between the striker header shape and the cylindrical shell surface was determined by general contact with the penalty approach. The friction coefficient at the contact area was defined with 0.3.

Before performing the numerical simulations on the test model, the convergence tests were carried out to choose the optimum mesh size. For models CY-2 to CY-9 and R3 to R6, the mesh size is $2 \mathrm{~mm} \times 2 \mathrm{~mm}$, while that of models RS-I to RS-C- 4 is $5 \mathrm{~mm} \times 5 \mathrm{~mm}$ in the contact area and $10 \mathrm{~mm} \times 10 \mathrm{~mm}$ in the outer contact area. These mesh sizes are enough to capture the collision responses of test models.

For the material definition of collision analysis, the formula reported by Do et al. ${ }^{20}$ were used. These formulations were derived based on the results of a large number of dynamic tensile tests with different marine steels. In these formulations, the strain-rate hardening effects were also considered. In this study, the strain rates were generated with various values from $10 \mathrm{~s}^{-1}, 20 \mathrm{~s}^{-1}, 50 \mathrm{~s}^{-1}, 70 \mathrm{~s}^{-1}, 100 \mathrm{~s}^{-1}$, to $150 \mathrm{~s}^{-1}$, as shown in Figure 1.

During the manufacturing processes, stiffened cylinders were exposed by cold bending and welding procedures. These residual stresses should be considered in numerical modeling. In this study, both residual stresses from cold bending and welding have been included in numerical analysis, as illustrated in Figures 2,3 .

The numerical simulations were divided into two steps. First, the models generated damage by colli- 


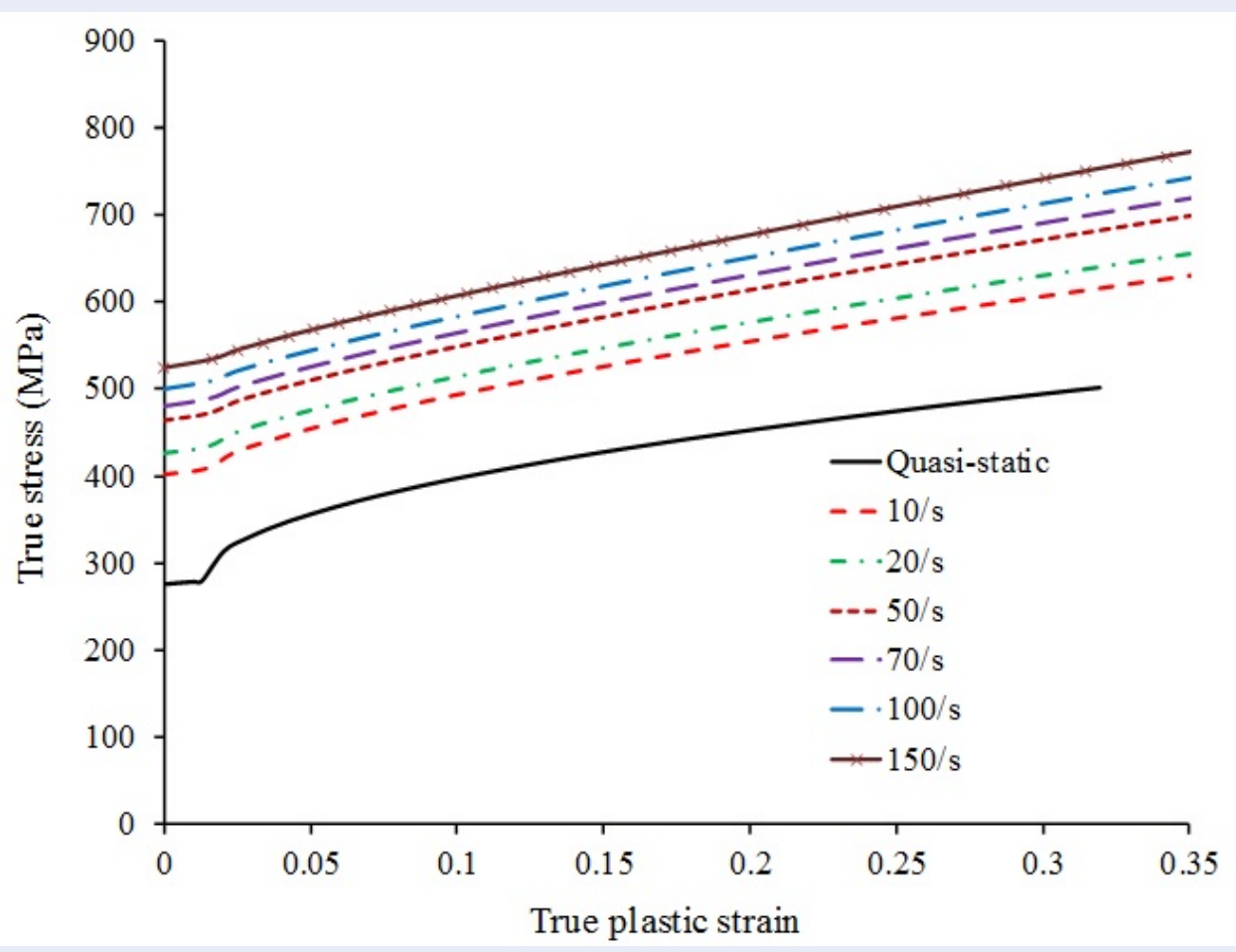

Figure 1: True stress-strain curve at various strain rates for RS-C-3 model.

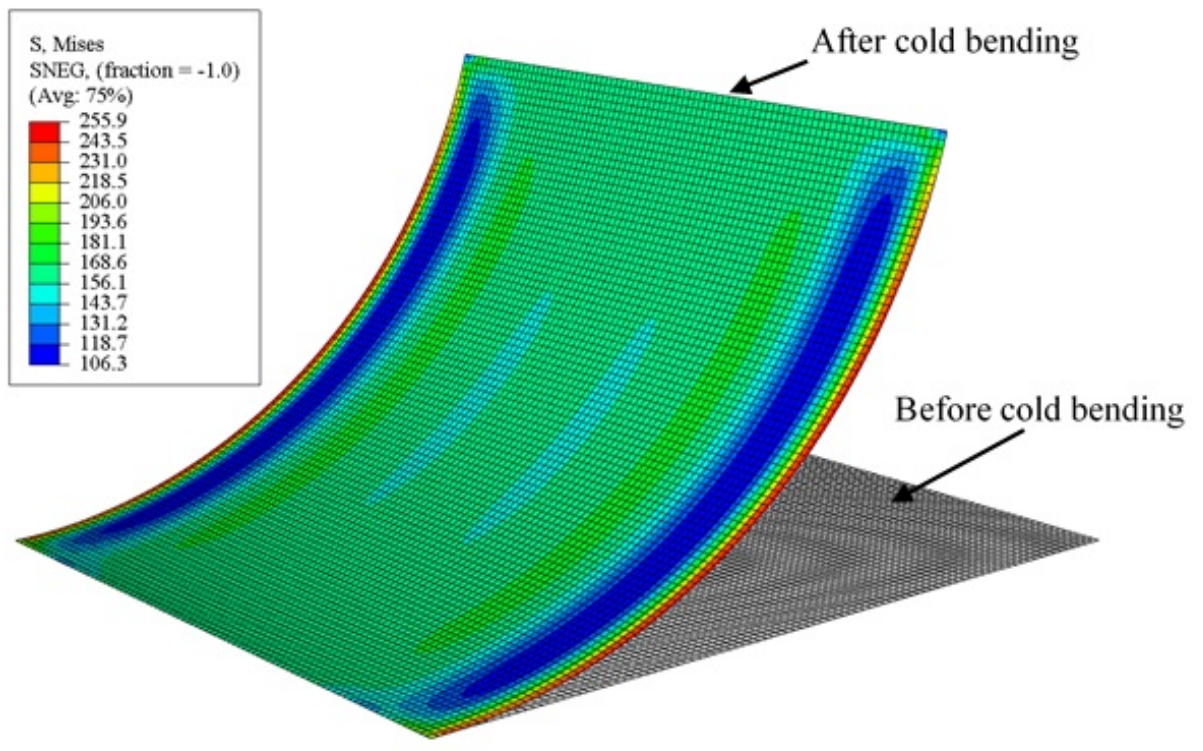

Figure 2: Cold bending residual stress distribution for model RS-II. 


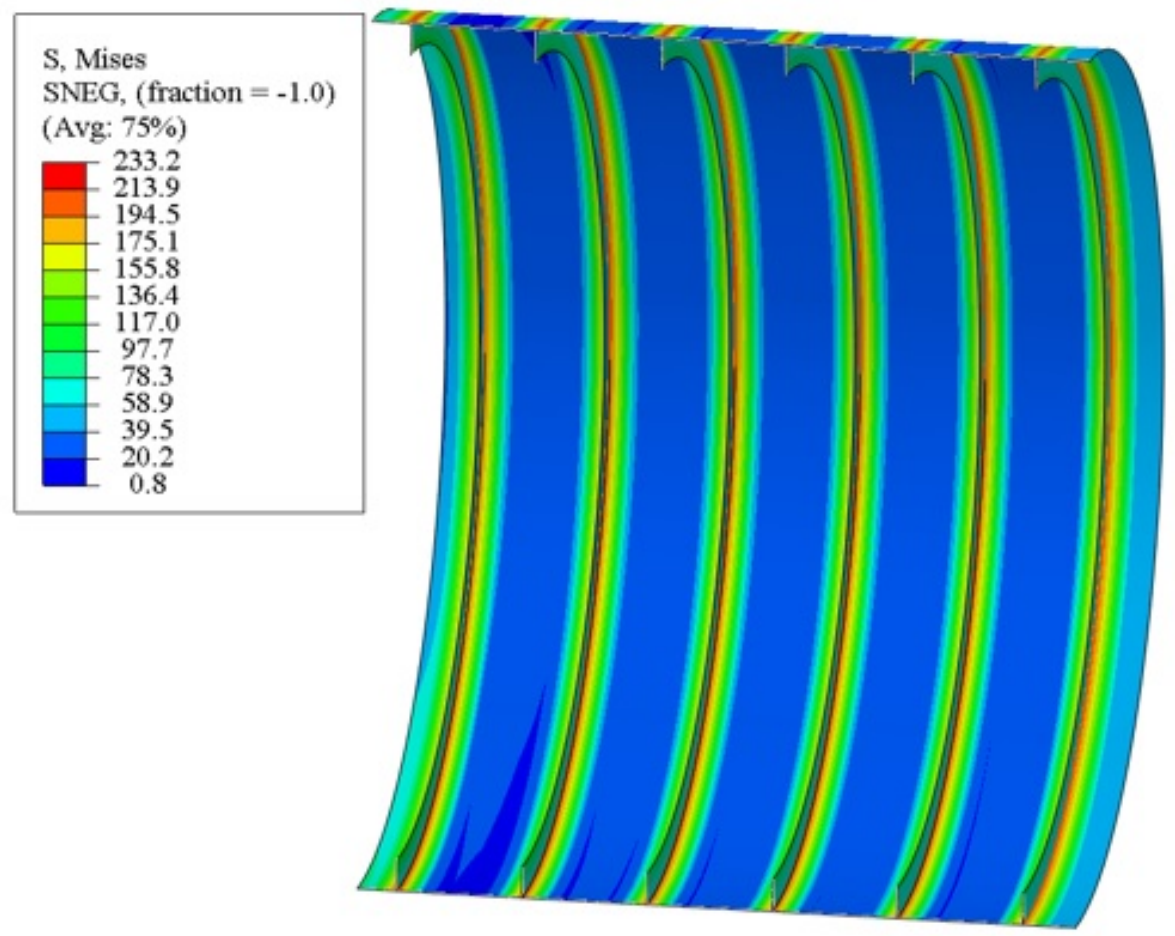

Figure 3: Welding of residual stress distribution for model RS-II.

sion analysis. Second, all collision models were subsequently performed under collapse analysis. The details of the boundary condition and loads were shown in Figure 4. Furthermore, during the first step, the initial imperfection was inputted into modeling. The best solution was inputted directly to measure imperfect values into modeling models. This data is not only considering local buckling mode but also includes overall buckling modes. Therefore, the collapse shapes were correlated between numerical and experimental results. However, if the measurement of imperfect data was not provided, it could be used for some formulations to determine the imperfect magnitudes. For this goal, it performed buckle analyses and obtained the eigenvalue buckle. The first buckling mode was generally chosen for generating the initial imperfection. The problem was how large imperfection magnitude was introduced. Additionally, the maximum initial imperfection magnitude values were $0.5 \%$ of the cylinder radius $R$, which corresponded to the upper limit of tolerable imperfection for stringerstiffened cylinders by API ${ }^{23}$. Teguh et al. ${ }^{24}$ determined that the initial imperfection was approximately $0.4 t$ ( $t$ is shell thickness) after comparing the numerical results and test results of small-scaled cylinder models. In this research, the imperfection magnitude was determined by approximation $0.5 t$. These values were obtained by comparing the numerical results and test results and API rules ${ }^{23,24}$. To consider the failure modes of local buckling and general buckling, the combination of the first and sixth eigen buckling modes were included.

\section{Validation of numerical modeling strategy}

The test results and the numerical analysis are presented in Table 3. The accuracy of the numerical simulations is determined by uncertainty modeling factor $X_{m}$ (numerical result/ test result). The mean of $X_{m}$ is 0.969 , and there is a small COV of $5.27 \%$ indicated in this table. Furthermore, axial compressive strength and axial strain curve relationships are shown in Figure 5. A close agreement curve was obtained between numerical results and test results. In addition, the deformed shapes of models RS-C-1,2 are also compared in Figure 6. It is clear that the similar deformed shapes between numerical predictions and test results are archived. Therefore, it can be used for further case studies for reality offshore cylinders to promote design codes or validate the collision issues. 
Table 1: Measured dimensions andmaterial data of specimens

\begin{tabular}{|c|c|c|c|c|c|c|c|c|c|c|}
\hline & & CY-2 & CY-3 & CY-4 & CY-5 & CY-6 & CY-7 & CY-8 & CY-9 & RS-I \\
\hline $\begin{array}{l}\text { Radius } \\
(\mathrm{mm})\end{array}$ & $R$ & 160 & 160 & 160 & 160 & 160 & 160 & 160 & 160 & 400 \\
\hline $\begin{array}{l}\text { Thickness } \\
(\mathrm{mm})\end{array}$ & $t$ & 0.6 & 1.2 & 1.2 & 0.6 & 1.2 & 1.2 & 0.6 & 0.6 & 3.96 \\
\hline $\begin{array}{l}\text { Total } \\
\text { length } \\
(\mathrm{mm})\end{array}$ & $L$ & 200 & 200 & 400 & 400 & 400 & 320 & 96 & 96 & 1060 \\
\hline $\begin{array}{l}\text { Ring- } \\
\text { stiffener } \\
\text { spacing } \\
(\mathrm{mm})\end{array}$ & $l$ & 40 & 40 & 80 & 80 & 80 & 80 & 24 & 24 & 200 \\
\hline $\begin{array}{l}\text { Yield stress } \\
(\mathrm{MPa})\end{array}$ & $\sigma_{Y}$ & 344 & 342 & 324 & 349 & 324 & 352 & 376 & 376 & 306.5 \\
\hline $\begin{array}{l}\text { Elasticity } \\
\text { modulus } \\
(\mathrm{GPa})\end{array}$ & $E$ & 201 & 201 & 201 & 201 & 201 & 201 & 201 & 201 & 206 \\
\hline $\begin{array}{l}\text { Number of } \\
\text { rings }\end{array}$ & $N_{s}$ & 5 & 5 & 5 & 5 & 4 & 4 & 4 & 4 & 6 \\
\hline $\begin{array}{l}\text { Web height } \\
\text { of stiffener } \\
(\mathrm{mm})\end{array}$ & $h_{w}$ & 4.8 & 6.72 & 4.8 & 4.8 & 3 & 3 & 3 & 3 & 35 \\
\hline $\begin{array}{l}\text { Web thick- } \\
\text { ness of stiff- } \\
\text { ener (mm) }\end{array}$ & $t_{w}$ & 0.6 & 0.84 & 0.6 & 0.6 & 0.6 & 0.6 & 0.6 & 0.6 & 3.94 \\
\hline $\begin{array}{l}\text { Flange } \\
\text { width of } \\
\text { stiffener } \\
(\mathrm{mm})\end{array}$ & $b_{f}$ & 0 & 0 & 0 & 0 & 4 & 4 & 6 & 6 & 0 \\
\hline $\begin{array}{l}\text { Flange } \\
\text { thickness } \\
\text { of stiffener } \\
(\mathrm{mm})\end{array}$ & $t_{f}$ & 0 & 0 & 0 & 0 & 0.6 & 0.6 & 0.84 & 0.84 & 0 \\
\hline
\end{tabular}

\section{PARAMETRIC STUDY}

In this section, the ultimate strength of the damaged cylinder with $\mathrm{T}$ type ring-stiffeners, as illustrated in Table 4 is now studied under axial compressive loads, lateral pressure, and under a combination of these two load cases. These models are the real design of stiffened cylinders of the submarine design concepts or spars and TLPs given in ABS ${ }^{14}$. The details of scantlings and material data for each model are indicated in this table.

A series of FEA models were carried out with various velocities from $1 \mathrm{~m} / \mathrm{s}$ to $10 \mathrm{~m} / \mathrm{s}$. The striking masses were assumed as 10 tons, 20 tons, 50 tons, and 100 tons. The range of ratio $\mathrm{R} / \mathrm{t}$ was determined from 97 to 501 , and the range of dent depth to a radius of cylinder $d / R$ from 0 to 0.07 . After generating damages, all models were then applied under radial pressure or axial compression-only or combination of the two of them.

\section{Deriving equations to assess the dent depth}

Before deriving equations to forecast the residual strength of dented ring-stiffened cylinders, the formulations for assessing the maximum permanent dent depth were provided as Eqs. 1-12. The details of derived formulation procedures to assess the per- 
Table 2: Measured dimensions and material data of specimens

\begin{tabular}{|c|c|c|c|c|c|c|c|c|c|}
\hline & & RS-C-1 & RS-C-2 & RS-C-3 & RS-C-4 & R3 & R4 & R5 & R6 \\
\hline Radius (mm) & $R$ & 400 & 400 & 550 & 550 & 159.8 & 159.8 & 160 & 160 \\
\hline $\begin{array}{l}\text { Thickness } \\
(\mathrm{mm})\end{array}$ & $t$ & 3.96 & 3.95 & 4.97 & 4.94 & 0.6 & 0.6 & 0.6 & 0.6 \\
\hline $\begin{array}{l}\text { Total length } \\
(\mathrm{mm})\end{array}$ & $L$ & 1060 & 1060 & 1060 & 1060 & 96 & 96 & 288 & 288 \\
\hline $\begin{array}{l}\text { Ring-stiffener } \\
\text { spacing }(\mathrm{mm})\end{array}$ & $l$ & 200 & 200 & 200 & 200 & 24 & 24 & 96 & 96 \\
\hline $\begin{array}{l}\text { Yield stress } \\
(\mathrm{MPa})\end{array}$ & $\sigma_{Y}$ & 302.2 & 309 & 274.9 & 274.9 & 387 & 387 & 387 & 387 \\
\hline $\begin{array}{l}\text { Elasticity } \\
\text { modulus } \\
(\mathrm{GPa})\end{array}$ & $E$ & 206 & 206 & 202.4 & 202.4 & 208 & 208 & 208 & 208 \\
\hline $\begin{array}{l}\text { Web height of } \\
\text { stiffener }(\mathrm{mm})\end{array}$ & $N_{s}$ & 6 & 6 & 8 & 8 & 3 & 3 & 2 & 2 \\
\hline $\begin{array}{l}\text { Web thickness } \\
\text { of stiffener } \\
(\mathrm{mm})\end{array}$ & $h_{w}$ & 35 & 35 & 40 & 40 & 3 & 3 & 6.4 & 6.4 \\
\hline $\begin{array}{l}\text { Flange width } \\
\text { of stiffener } \\
(\mathrm{mm})\end{array}$ & $t_{w}$ & 3.97 & 4.0 & 5.81 & 5.81 & 0.6 & 0.6 & 0.6 & 0.6 \\
\hline $\begin{array}{l}\text { Flange thick- } \\
\text { ness of } \\
\text { stiffener }(\mathrm{mm})\end{array}$ & $b_{f}$ & 0 & 0 & 0 & 0 & 6 & 6 & 0 & 0 \\
\hline $\begin{array}{l}\text { Web height of } \\
\text { stiffener (mm) }\end{array}$ & $t_{f}$ & 0 & 0 & 0 & 0 & 0.84 & 0.84 & 0 & 0 \\
\hline
\end{tabular}

manent dent depth of ring-stiffened cylinders is given $\quad \beta$ : impact angle ( $\mathrm{rad})$;

in reference Do et al. ${ }^{22}$.

$\delta_{d}=\frac{d}{R}=4.91 C_{S} C_{L} C_{\beta}\left(\lambda_{E}\right)^{0.71} ;$ Mean equation

$\delta_{d}=\frac{d}{R}=5.16 C_{S} C_{L} C_{\beta}\left(\lambda_{E}\right)^{0.71} ;$ Design equation

Where $C_{S}$ is the striker header shape factor (when the hemisphere striker is applied $C_{S}=1 ; C_{S}=0.81$ : when knife-edge striker header is applied; $C_{S}=0.68$ : when rectangular striker header is applied)

$$
C_{L}=\operatorname{Exp}\left(-1.55\left(\frac{x}{L}\right)^{0.57}\right)
$$

$C_{L}$ : impact location factor;

$x$ : distance from impact position to mid-length of cylinder;

$L$ : overall length of cylinder;

$$
C_{\beta}=0.139 \beta^{2}-0.0 .437 \beta+1
$$

$C_{\beta}$ : impact angle factor;

$$
\lambda_{E}=\frac{E_{k}}{E_{a}}
$$

$$
E_{k}=\frac{1}{2} m v^{2} ; \text { Kinetic energy }
$$

$$
E_{a}=\frac{\sigma_{Y}+\sigma_{T}}{2} \varepsilon_{T} V_{s t r}
$$

Strain energy absorption capacity

$$
\begin{aligned}
V_{\text {str }} & =V_{\text {shell }}+V_{\text {ring-stiffener }} \\
& =A . L+V_{\text {ring-stiffener }}
\end{aligned}
$$

- For general structural steel:

$$
\begin{gathered}
\frac{\sigma_{T}}{\sigma_{Y}}=\left\{1+0.664\left(\frac{E}{1000 \sigma_{Y}}\right)^{2.4}\right\} \\
\frac{\varepsilon_{T}}{\varepsilon_{Y}}=336\left(\frac{E}{1000 \varepsilon_{Y}}\right)^{2.52}
\end{gathered}
$$

- For marine structural steel: 
Table 3: Comparison between numerical simulations and test results

\begin{tabular}{|c|c|c|c|c|}
\hline Model & $\begin{array}{l}\text { Experimental result } \\
\text { (Mpa) }\end{array}$ & $\begin{array}{l}\text { Numerical } \\
\text { (Mpa) }\end{array}$ & result & Ratio (Exp./Num.) \\
\hline CY-2 & 271.8 & 276.9 & & 0.982 \\
\hline CY-3 & 266.8 & 289.2 & & 0.922 \\
\hline CY-4 & 268.9 & 283.9 & & 0.947 \\
\hline CY-5 & 212.9 & 215.7 & & 0.987 \\
\hline CY-6 & 257.6 & 281.7 & & 0.915 \\
\hline CY-7 & 253.4 & 268.2 & & 0.945 \\
\hline CY-8 & 225.6 & 252.8 & & 0.892 \\
\hline CY-9 & 229.4 & 251.7 & & 0.911 \\
\hline RS-I & $2.16\left(\mathrm{P}_{c}\right)$ & $2.09\left(\mathrm{P}_{c}\right)$ & & 1.033 \\
\hline RS-C-1 & $1.40\left(\mathrm{P}_{c}\right)$ & $1.36\left(\mathrm{P}_{c}\right)$ & & 1.029 \\
\hline RS-C-2 & $1.65\left(\mathrm{P}_{c}\right)$ & $1.59\left(\mathrm{P}_{c}\right)$ & & 1.038 \\
\hline RS-C-3 & $1.90\left(\mathrm{P}_{c}\right)$ & $1.87\left(\mathrm{P}_{c}\right)$ & & 1.016 \\
\hline RS-C-4 & $1.80\left(\mathrm{P}_{c}\right)$ & $1.71\left(\mathrm{P}_{c}\right)$ & & 1.053 \\
\hline R3 & 94.03 & 96.8 & & 0.970 \\
\hline R4 & 199.0 & 204.0 & & 0.980 \\
\hline R5 & 88.0 & 96.0 & & 0.920 \\
\hline \multirow[t]{3}{*}{ R6 } & 74.7 & 80.0 & & 0.930 \\
\hline & & & Mean & 0.969 \\
\hline & & & $\mathrm{COV}$ & $5.27 \%$ \\
\hline
\end{tabular}

Table 4: Details of scantlingsand material data of model

\begin{tabular}{llllllllllll}
\hline Sym. & Unit & RS-1 & RS-2 & RS-3 & RS-4 & RS-5 & RS-6 & RS-7 & RS-8 & RS-9 & RS-10 \\
$R$ & $\mathrm{~mm}$ & 3100 & 3023 & 3175 & 3100 & 2550 & 5150 & 2500 & 3500 & 3500 & 3180 \\
$t$ & $\mathrm{~mm}$ & 30 & 25 & 20 & 23 & 26 & 30 & 9.5 & 11.5 & 10.5 & 6.35 \\
$L_{c}$ & $\mathrm{~mm}$ & 12600 & 10240 & 10500 & 12500 & 14850 & 16900 & 10500 & 12500 & 10500 & 10500 \\
$l$ & $\mathrm{~mm}$ & 430 & 3048 & 840.7 & 430 & 450 & 650 & 750 & 840.7 & 750 & 840.7 \\
$\sigma_{Y}$ & $\mathrm{MPa}$ & 645 & 754 & 645 & 645 & 827 & 645 & 380 & 276 & 276 & 345 \\
$E$ & $\mathrm{GPa}$ & 206 & 206 & 206 & 206 & 210 & 206 & 205 & 199 & 199 & 199 \\
$n_{r}$ & {[]} & 29 & 4 & 12 & 23 & 33 & 26 & 14 & 15 & 14 & 12 \\
$h_{r w}$ & $\mathrm{~mm}$ & 210 & 214 & 95.20 & 180 & 178 & 262 & 190 & 95.2 & 150 & 95.2 \\
$t_{r w}$ & $\mathrm{~mm}$ & 19.0 & 15 & 11.00 & 13 & 26 & 16.5 & 9.5 & 11.5 & 10.5 & 6.35 \\
$w_{r f}$ & $\mathrm{~mm}$ & 155 & 280 & 76.2 & 90 & 102 & 231 & 150 & 76.2 & 220 & 76.2 \\
$t_{r f}$ & $\mathrm{~mm}$ & 19 & 17 & 11.00 & 23 & 14 & 24 & 9.5 & 11.5 & 10.5 & 6.35 \\
$R / t$ & & 103 & 121 & 159 & 135 & 97 & 172 & 263 & 304 & 333 & 501 \\
\hline
\end{tabular}



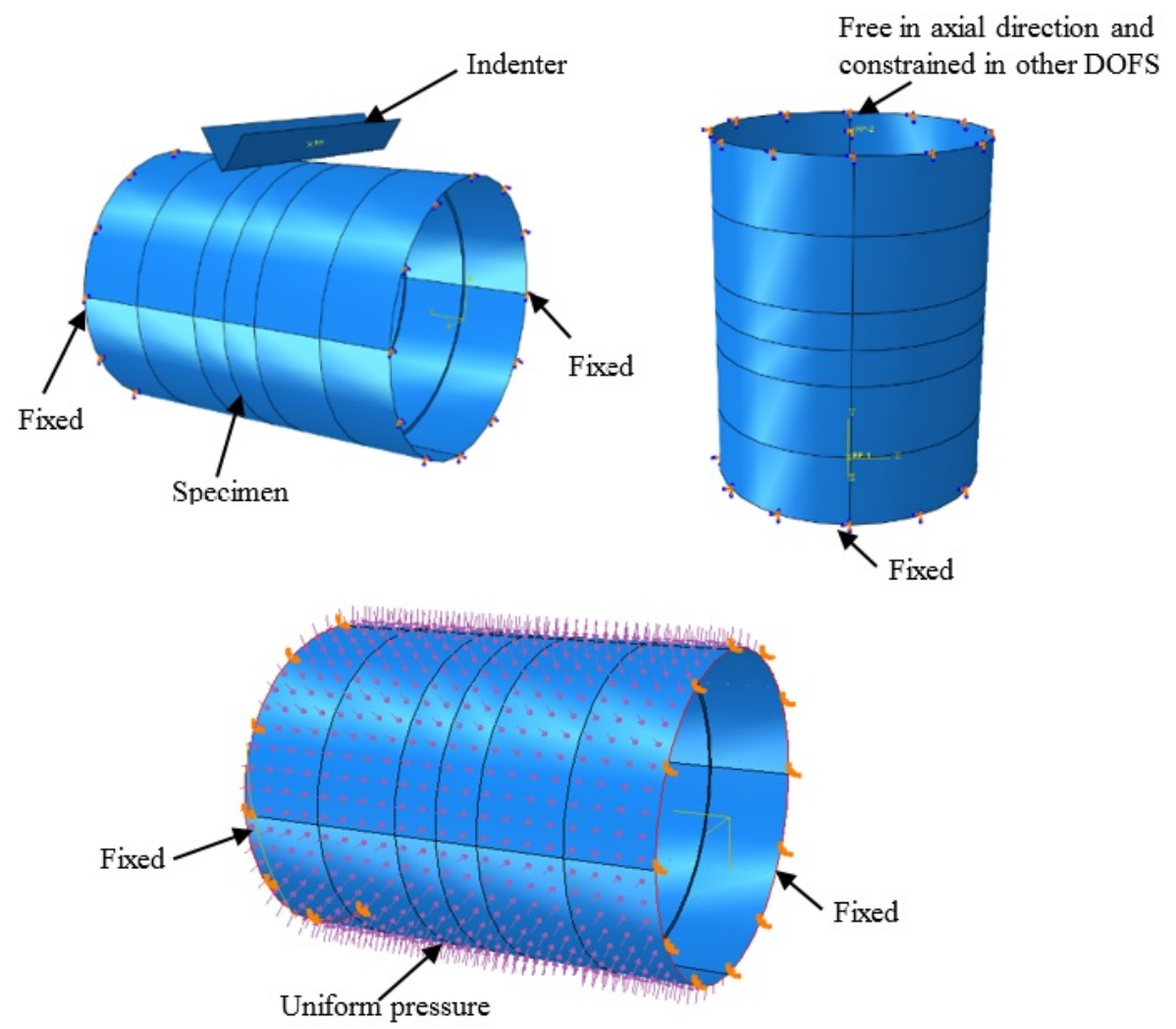

Figure 4: FEM setup for collision simulations and collapse analysis.

$$
\begin{gathered}
\frac{\sigma_{T}}{\sigma_{Y}}=\left\{1+1.3\left(\frac{E}{1000 \sigma_{Y}}\right)^{2.5}\right\} \\
\frac{\varepsilon_{T}}{\varepsilon_{Y}}=320\left(\frac{E}{1000 \varepsilon_{Y}}\right)^{1.76}
\end{gathered}
$$

\section{Axial compression}

In this section, the effects of dent depth on the ultimate strength of the cylinder under axial compression were investigated. Then, the proposed equations were derived through regression analysis. In numerical simulations, all degrees of freedom were fixed at the end of the cylinder but allowed axial compression at one side. Figure 7 shows the average axial stressstrain curves varying the ratio of dent depth over the radius of cylinder $d / R$. It is clear that the ultimate strength of the dented case is not rapidly decreased when compared to intact cases. It means the effect of dent depth is not significant on the reduction of ultimate strength.
The deformed shape of the intact case and the dented case are compared in Figure 8. The failure mode is local buckling at mid-span of cylinders for both intact and dented model. However, the damaged area of the dented case is larger than that of an intact case. In the dented cases, the collision damage was caused by initial buckling and led to reducing the cylinder stiffness. Then, the structures were collapsed after reaching the ultimate strength.

Figure 9 shows the variation of ultimate strength $\sigma_{x u}$ in terms of $R / t$ and $d / R$. From Figure 9 it is evident that the ratio $d / R$ (permanent dent depth/radius of the cylinder) is an important parameter affecting not only the ultimate strength but also the reduction due to damage. Therefore, it can be used as the main parameter to derive the equation for forecasting the residual strength of these structures. Through a regression analysis approach, the empirical equation was derived to assess the reduction factor $R_{x u}$ as Eq. 13. Once the ultimate strength of an intact cylinder $\sigma_{x u \text {-intact }}$ is calculated, the residual strength can be obtained by multiplying it by the strength reduction factor $R_{x u}$ as defined in Eq. 13. The mean of numerical results to 

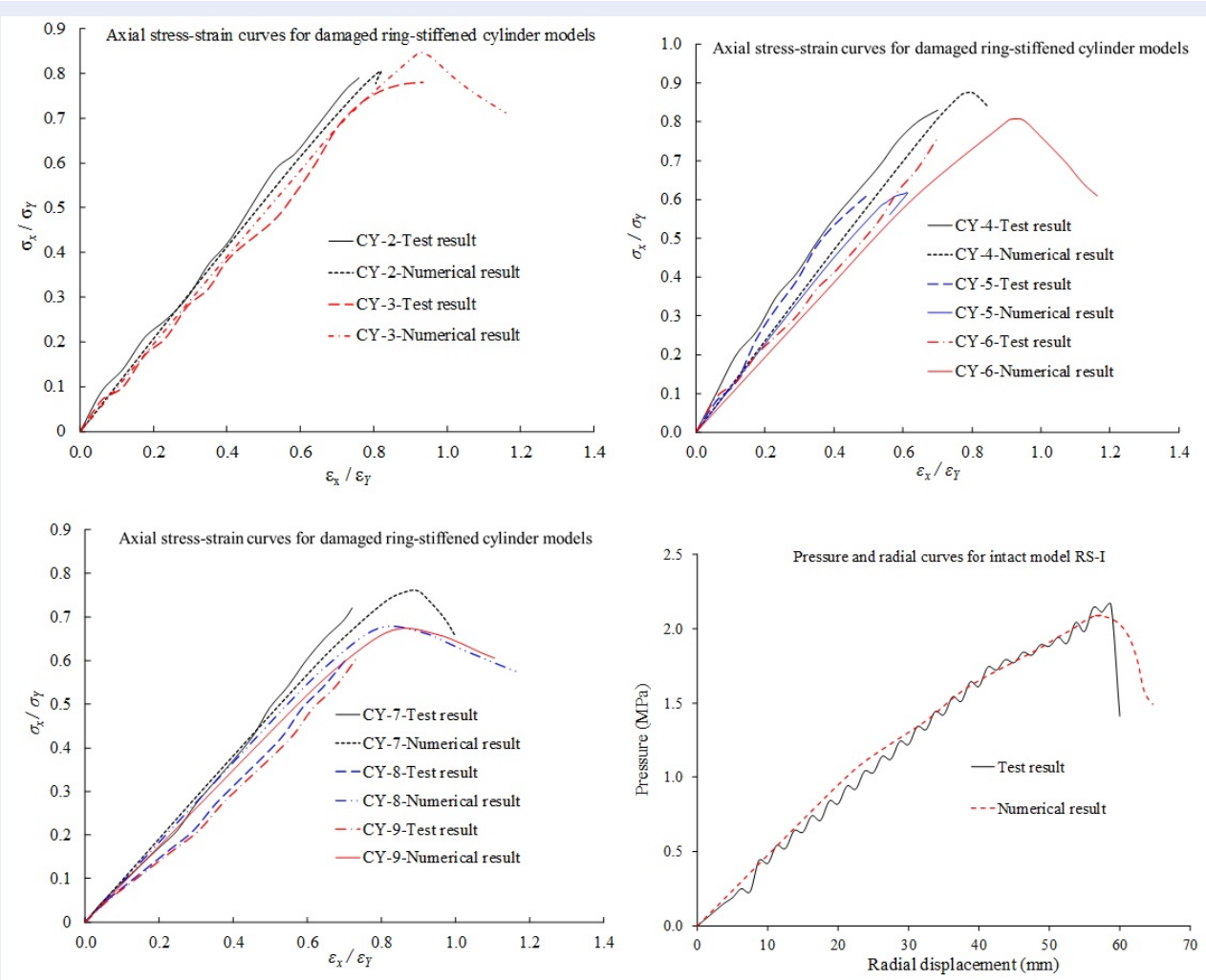

Figure 5: Comparison of test results with numerical results.
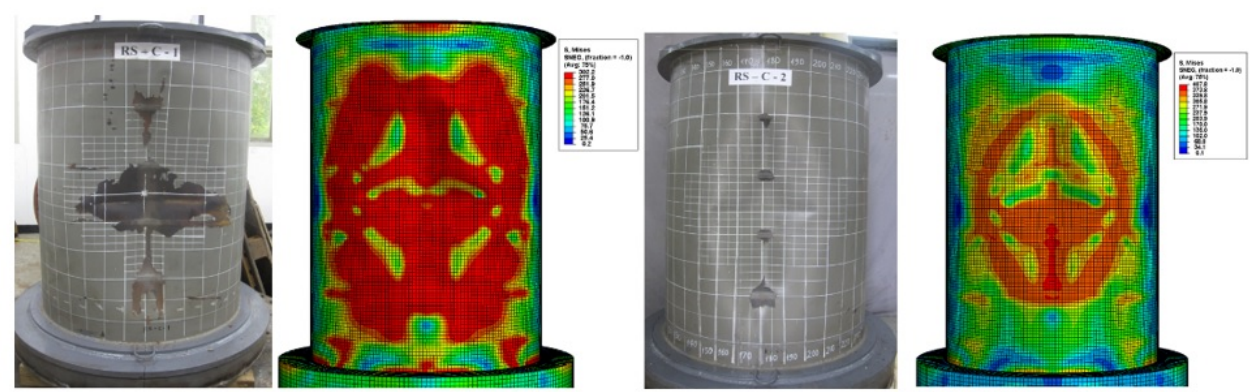

Figure 6: Comparison of deformed shapes between test results and numerical results. 


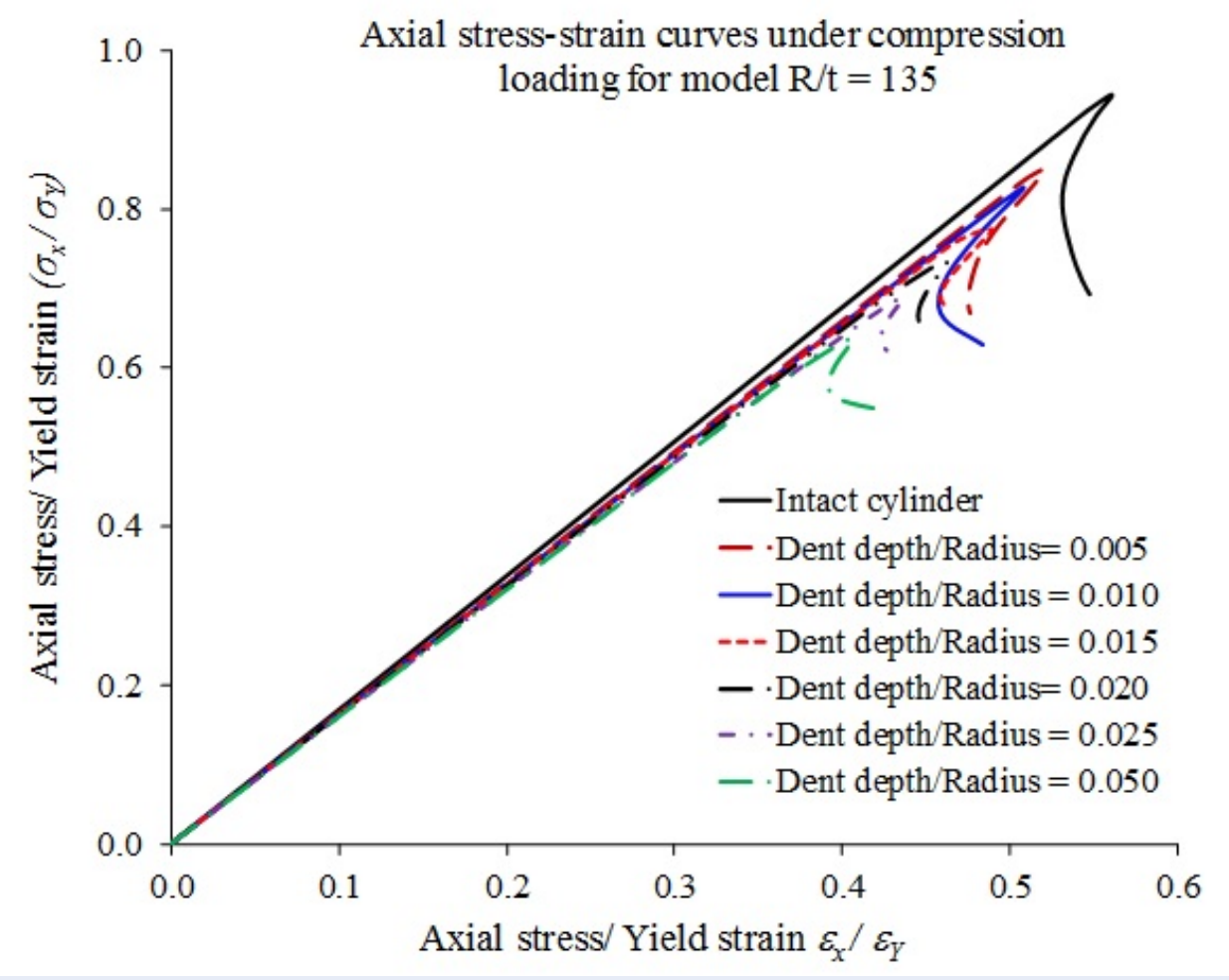

Figure 7: Stress-strain relationship curves (model RS-4).

\begin{tabular}{|l|}
\hline S. Mises \\
SNEG. (fraction = -1.0) \\
(Avg: 75\%) \\
644.76 \\
591.16 \\
537.56 \\
483.96 \\
430.37 \\
376.77 \\
323.17 \\
269.57 \\
215.97 \\
162.37 \\
108.77 \\
55.17 \\
1.57 \\
\hline
\end{tabular}
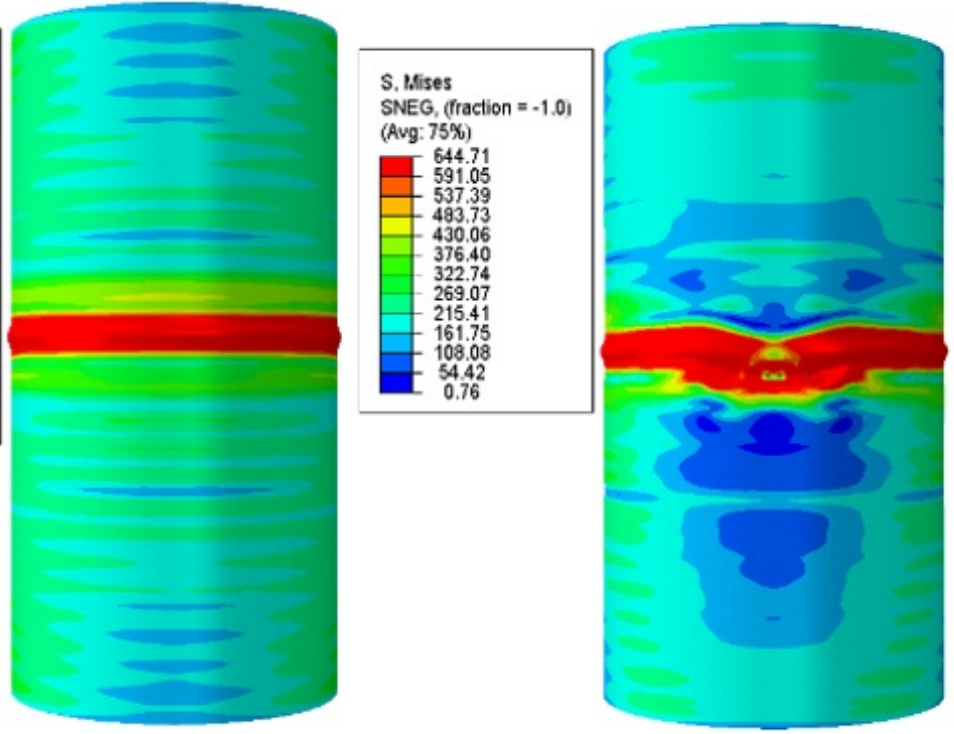

Figure 8: Collapsed shape of the intact and dented model under axial compression. 
predict formulae of 150 data is 1.0002 , with a COV of $3.27 \%$.

$$
R_{x u}=\frac{\sigma_{x u \_d a m .}}{\sigma_{x u \_i n .}}=\exp \left\{32 *\left(\frac{d}{R}\right)^{2}-\left(\frac{d}{R}\right)\right\}
$$

\section{Radial pressure}

The same processes as the previous section, the effects of dent depth on reduction in the ultimate strength of cylinder under radial pressure were investigated. Figure 10 illustrates the collapsed shape between an intact case and a damaged case with $d / R=0.028$. It is evident that the collapsed area of dented cases is larger and severer than that of intact cases. Next, Figure 11 describes the relationship curve between radial pressure and displacement. It can be seen that the dent depth was significantly affected by the reduction of ultimate strength owning to the loss of cylinder stiffness. It is contrary to the compressive loading cases.

Figure 12 indicates the verification of the formula to assess the residual strength of locally dented ringstiffened cylinders under radial pressure. The equation was defined as a function to determine dent depth, as shown in Eq. 14. Where $R_{r u}$ means the reduction factor of radial pressure loadings. $P_{\text {intact }}$ is the radial collapse pressure of the intact model. $P_{\text {damage }}$ is the radial collapse pressure of the dented model. The mean of numerical results to predict formulae of 150 data is 0.998 , with a COV of $2.66 \%$.

$$
R_{r u}=\frac{P_{\text {damage }}}{P_{\text {intact }}}=\exp \left\{35 *\left(\frac{d}{R}\right)^{2}-\left(\frac{d}{R}\right)\right\}
$$

\section{Combination of radial pressure and axial compression}

In this part, the ultimate strength subjected to combined loading is studied while keeping radial pressure constant at several values and performing progressive collapse analysis for axial compression. Figure 13 shows the typical interaction curves together with the plots of the equation proposed in which the ultimate strength values are obtained using the formulas provided in previous sections. Here $P_{Y}$ means yield pressure calculated as $\sigma_{Y} t / R$. Radial pressure loading generally reduces the axial load carrying capacity to a lesser extent, but this fact becomes more pronounced as the radial pressure is close to the collapse pressure. The proposed equations to forecast the residual strength of the dented cylinder was illustrated as Eq. 15.The mean of numerical results to predicted formulae is 0.925 , with a COV of $5.62 \%$.

$$
\left(\frac{\sigma_{x}}{\sigma_{x u}}\right)^{2}+\left(\frac{P}{P_{u}}\right)^{2}=1
$$

\section{DISCUSSION}

From the research results, it is considered that the developed numerical techniques were reasonable accuracy and reliable between the predicted and test results for both collision and residual strength analysis. The mean of the $X_{m}$ (Uncertainty modeling factor) was 0.969 , together with $5.27 \%$ of COV (Coefficient of Variation). It is noted that the effect of trainrate hardening, residual stresses from cold bending and welding as well as initial imperfection were satisfactorily considered in numerical analysis. Therefore, the proposed numerical method can be applied to perform further parametric studies to develop the design equations.

A simple formula for forecasting the residual strength of ring-stiffened cylinder under axial compression, radial pressure, and combined both of them was provided as Eq. (13), Eq. (14) and Eq. (15), respectively. In these equations, the most suitable basis parameters have been included. And these equations have good accuracy with mean value $X_{m}$ around 1.0 and together with COV lower than $5.3 \%$. If the dent depth is known, the reduction factor $R_{u}$ is quickly predicted by applying Eqs. (13-15). Then, this factor can be multiplied with the ultimate stress or collapse pressure of each load of intact cylinders for obtaining the ultimate stress or collapse pressure of each load of dented cylinders.

There are two ways to calculate the ultimate compressive stress $\sigma_{x u}$ of an intact cylinder. First, performing the numerical analysis developed in this study for an intact ring-stiffened cylinder with consideration of initial imperfection and residual stresses. Second, the was calculated by using the proposed formulation provided by Cho et al. ${ }^{25}$.

The derived Eqs. (13-15) are convenient to use for the purpose of initial design and serviceability limit state evaluation of ring-stiffened cylinders under collisions of actual ocean cases. Based on the result of this study, it is suggested that more advanced and optimal structural designs should be considered in further case studies.

\section{CONCLUSION}

The main goal of this research was to derive the equations for evaluating the residual strength of locally dented ring-stiffened cylinders under combined loads. The findings are as follows: 


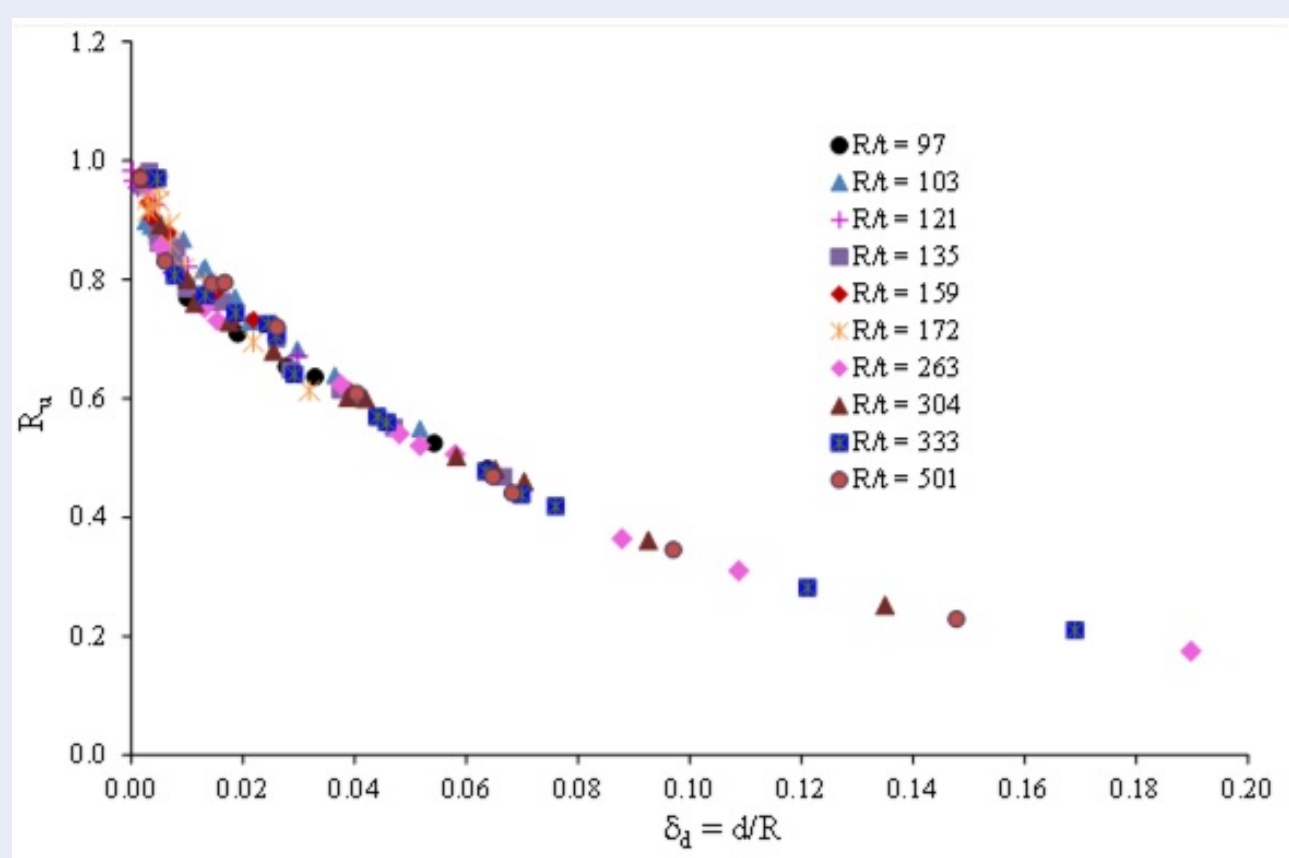

Figure 9: Verification of the empirical formula for residual strength of model under axial compression.
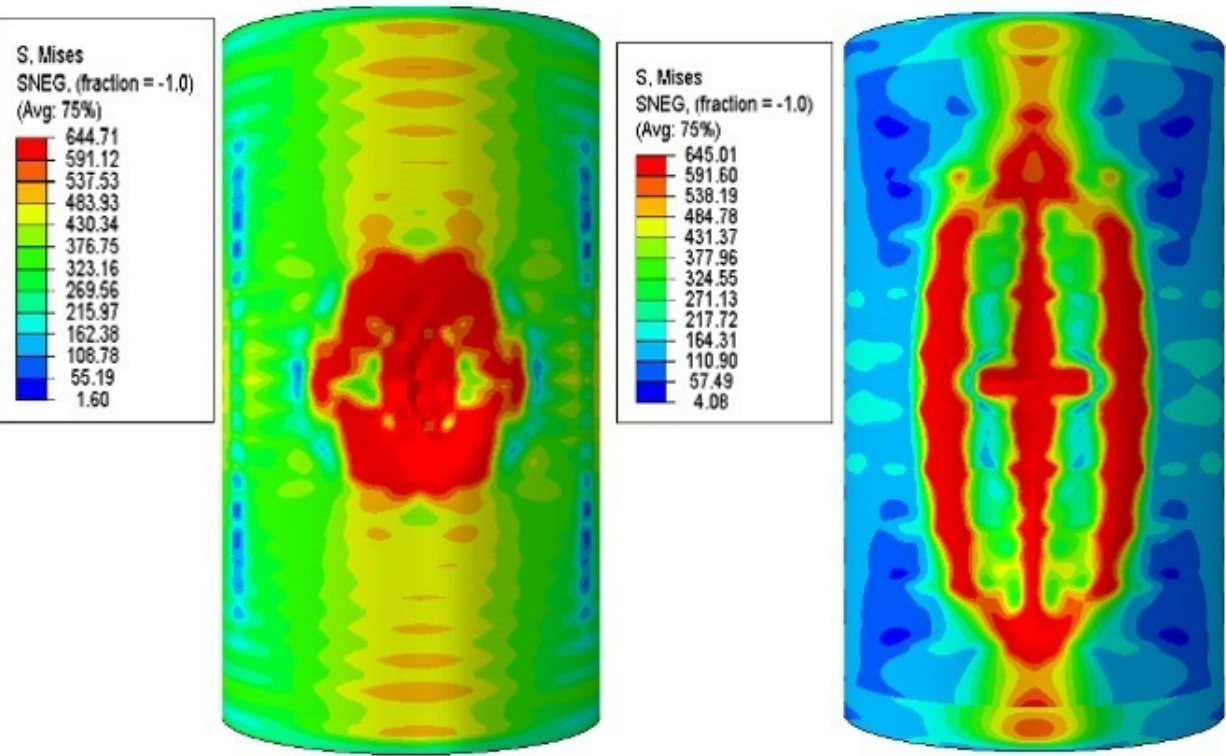

Figure 10: Deformation of the intact (left) and dented (right, $d / R=0.028$ ) cylinder model under radial pressure. 


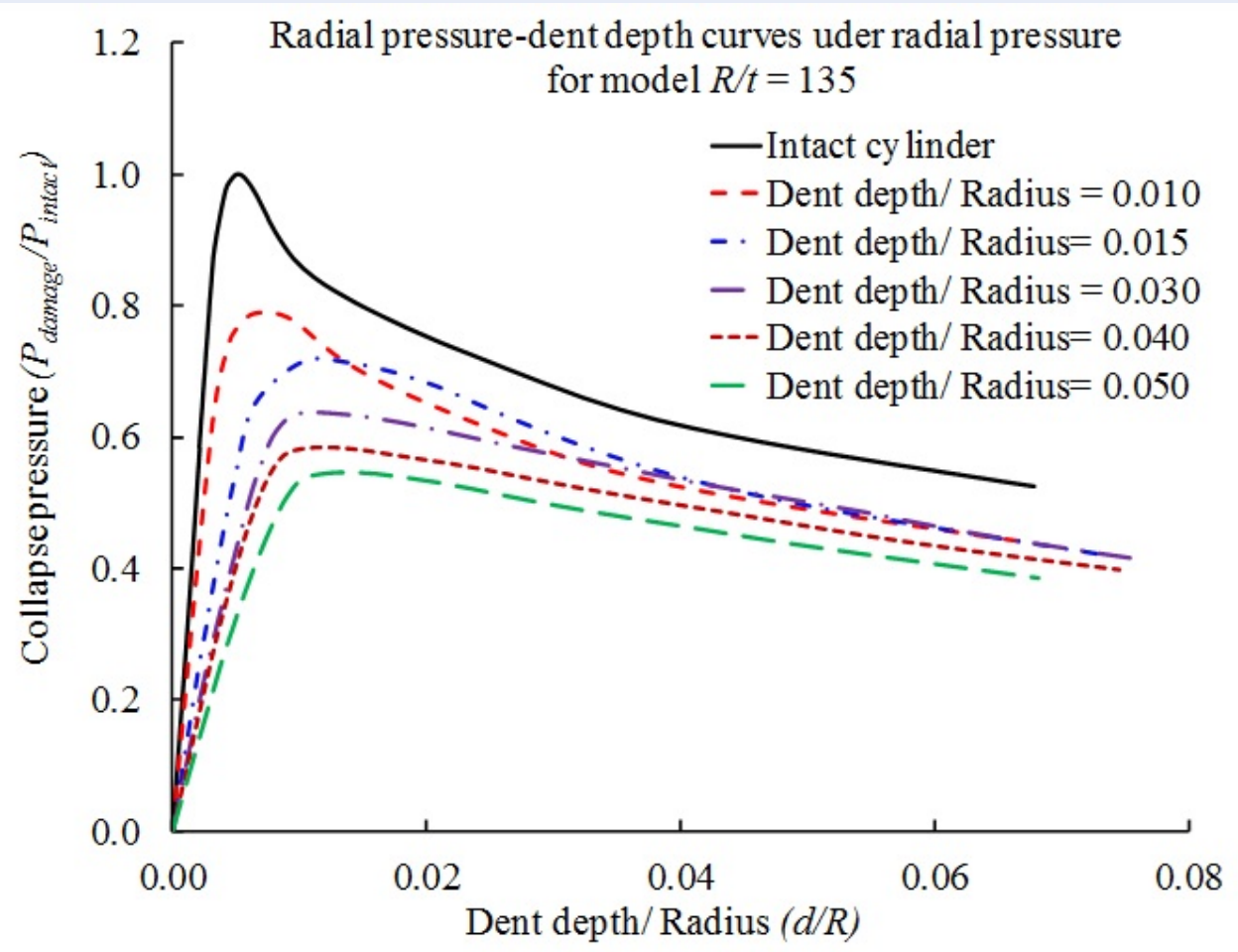

Figure 11: Radial pressure versus displacement curves for the ring-stiffened cylinder model RS-4.

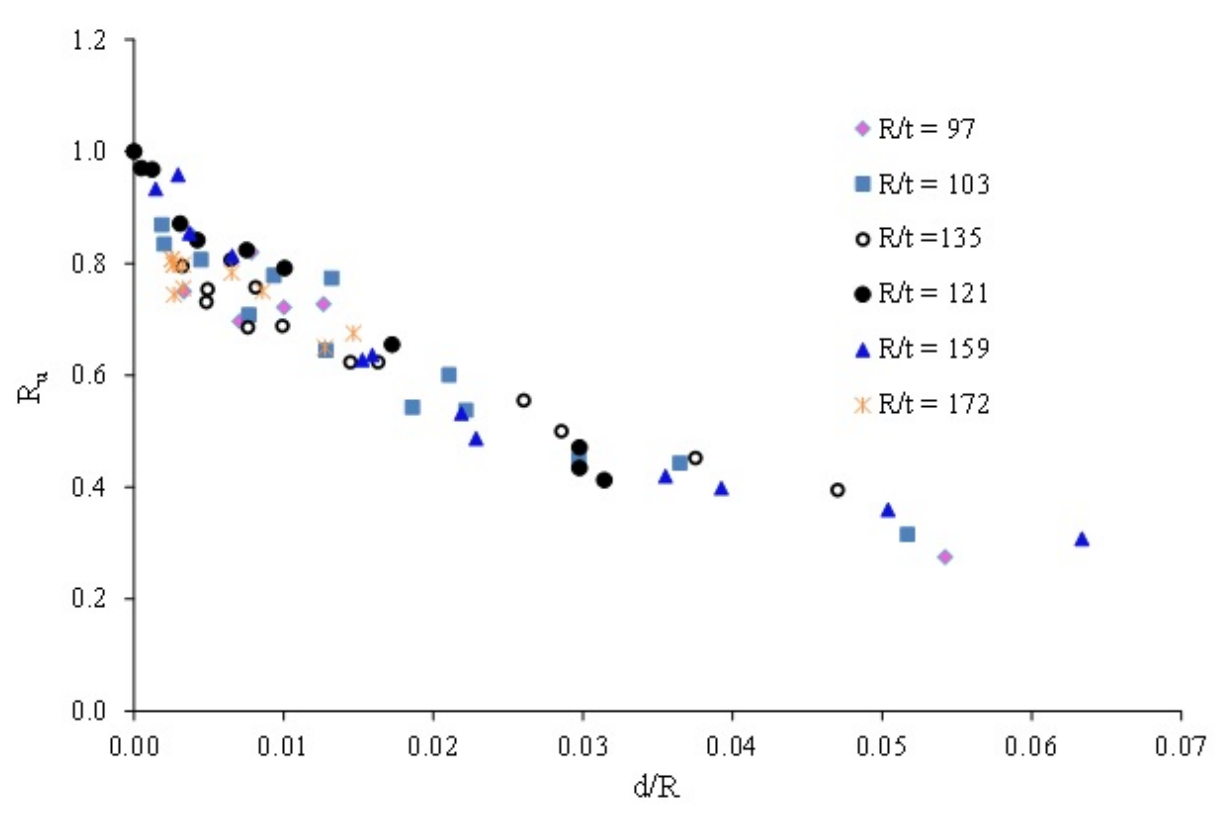

Figure 12: Verification of the empirical equation to forecast the residual strength of cylinders under radial pressure. 


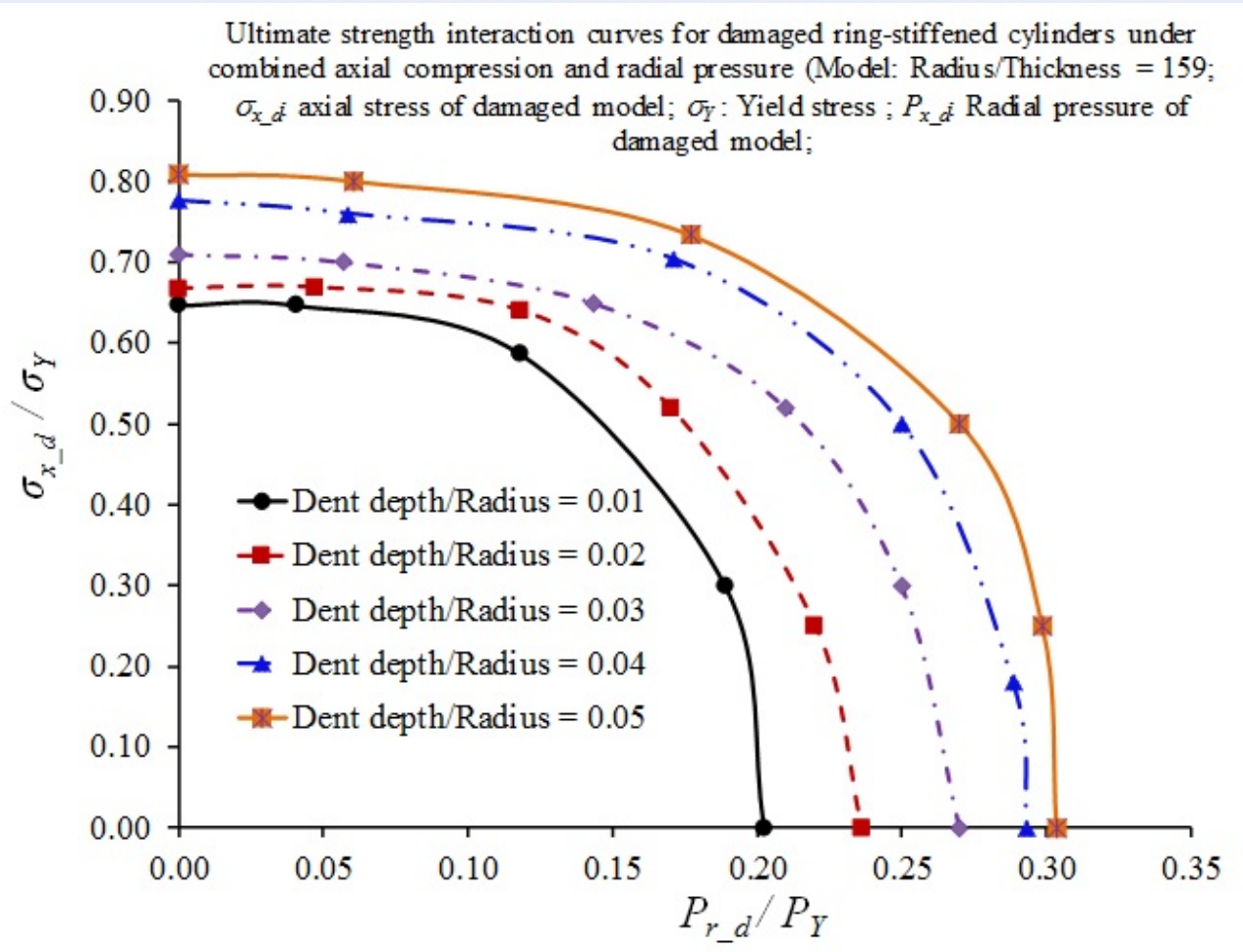

Figure 13: Ultimate strength interaction curves for damaged cylinders under combined loadings.

- The developed NFEM in this research has high accuracy and reliable to forecast the collapse responses of dented ring-stiffened cylinders under combined loads. Thus, it can be used for further case studies of reality offshore cylinders to promote design code or validate the collision issues.

- Based on the numerical results, it can be concluded that the most important parameter effect on the residual strength of the cylinder is the permanent dent depth. When the permanent dent depth is increased gradually, the residual strengths of the cylinders are decreased gradually because of the reduction of shell slenderness.

- The reduction in ultimate strength due to local damage under axial compression does not tend to increase dramatically as the dent depth increases. It has been found that the damaged zone becomes ineffective in carrying the axial load while the undamaged zone can still withstand axial compression without showing any sign of early instability and loss of stiffness.

- Under radial pressure, the damage causes the tripping of ring stiffeners and the leading overall collapse of the cylinder. Local damage results in a more significant reduction compared to axial compression.

- For combined loading, the axial load carrying capacity of damaged stiffened cylinders is not significantly affected by radial pressure unless radial pressure is close to its radial collapse pressure.

- For the first time, proposed formulations for reduction factors were derived. These factors can be multiplied with ultimate strength values obtained for intact cylinders in case of first-cut strength estimates if dent depth is known.

\section{LIST OF ABBREVIATIONS}

$R$ : Mean radius;

$h_{w}$ : Ring-stiffener web height;

$t$ : shell thickness;

$t_{w}$ : Web thickness;

$t_{f}$ : Flange thickness of stiffener;

$w_{f}$ : Flange width of stiffener;

$V_{\text {str }}$ : Structure volume;

$\delta_{d}$ : Non-dimensional dent depth;

$\lambda_{E}$ : Energy ratio;

$\sigma_{T}$ : Ultimate tensile stress; 
$\sigma_{Y}$ : Yield stress;

$Z$ : Batdorf slenderness parameter;

$m$ : striker mass;

$\sigma_{\text {xu_intact }}$ : ultimate strength of intact model;

$\sigma_{x u \_d a m}:$ residual strength of locally dented model;

$R_{u}$ : reduction factor;

\section{COMPLETING INTERESTS}

The author declares that there is no conflict of interest regarding the publication of this paper.

\section{AUTHOR'S CONTRIBUTIONS}

All the main contents, source-codes, and the computed results of this article have been developed by the author.

\section{ACKNOWLEDGEMENT}

This research is funded by the Vietnam National Foundation for Science and Technology Development (NAFOSTED) under grant number 107.01-2019.333.

\section{REFERENCES}

1. Kendrick SB. Analysis of results of static pressure tests of Chatham submarine models. Naval Construction Research Establishment, Dunfermline. 1955;p. R218.

2. Kendrick SB. Structure design of submarine pressure vessels. Naval Construction Research Establishment, Dunfermline. 1964;p. R483.

3. Cho SR, Muttaqie T, Do QT, Kim S, Kim SM, Han DH. Experimental investigations on the failure modes of ring-stiffened cylinders under external hydrostatic pressure. Int J Nav Archit Ocean Eng. 2018;10(6):711-729. Available from: https: //doi.org/10.1016/j.ijnaoe.2017.12.002.

4. Cho SR, Muttaqie T, Do QT, Ha Young S, Sohn J. Ultimate strength formulation considering failure mode interactions of ring-stiffened cylinders subjected to hydrostatic pressure. Ocean Eng. 2018;161:1-27. Available from: https://doi.org/10. 1016/j.oceaneng.2018.04.083.

5. Dowling PJ, Harding JE. Experimental behavior of ring and stringer stiffened shells. In: Buckling of Shells in Offshore Structures, ed by Harding JE, London, Granada. 1982;p. 73107.

6. Sridharan P, Walker AC. Experimental investigation of the buckling behaviour of stiffened cylindrical shells. UK Department of energy. 1980;p. OT-R7835.

7. Odland J. An experimental investigation of the buckling strength of the ring-stiffened cylinder shells under axial compression. Norwegian Maritime Research. 1980;40:22-39.

8. Miller CD. Summary of buckling tests on fabricated steel cylindrical shells in USA. In: Buckling of Shells in Offshore Structures, ed by Harding JE, London, Granada. 1982;p. 429-471.
9. Miller CD, Kinra RK. Tension and collapse tests of fabricated steel cylinders. Offshore Tech Conference. 1982;p. OTC 4218. Available from: https://doi.org/10.4043/4218-MS.

10. Bushnell D. Effect of cold bending and welding on buckling of ring-stiffened cylinders. Comput Struct. 1970;12:291-307. Available from: https://doi.org/10.1016/0045-7949(80)900280 .

11. Faulkner D. Effects of residual stresses on the ductile strength of plane welded grillages and of ring stiffened cylinders. Strain Analysis for Engineering Design. 1977;12:130-139. Available from: https://doi.org/10.1243/03093247V122130.

12. PSI 5500 . Specification for unfired fusion welded pressure vessels. British Standard Institution, London, UK. 2009;.

13. GL. Rules for Classification and Construction Naval Ship Technology. Lloydia (Cincinnati). 2009;1:1-12.

14. ABS. Rules for Building and Classing Underwater Vehicles, Systems and Hyperbaric Facilities. Facilities. 2011;1:1-8.

15. Harding JE, Onoufriou A. Behaviour of ring-stiffened cylindrical members damaged by local denting. J Constr Steel Res. 1995;33(3):237-257. Available from: https://doi.org/10.1016/ 0143-974X(94)00005-3.

16. Walker SM. Strength of damaged ring and orthogonally stiffened shells - part I Plain ring stiffened shells. Thin-Walled Structures. 1987;5:425-453. Available from: https://doi.org/10. 1016/0263-8231(87)90032-2.

17. Cerik BC. Ultimate strength of locally damaged steel stiffened cylinders under axial compression. Thin-Walled Struct. 2015;95:138-151. Available from: https://doi.org/10.1016/j. tws.2015.07.004

18. Do QT, Muttaqie T, Park S, Kyoung H, Cho SR. Predicting the collision damage of steel ring-sti ff ened cylinders and their residual strength under hydrostatic pressure. Ocean Eng. 2018;169:326-343. Available from: https://doi.org/10.1016/j. oceaneng.2018.09.041.

19. Cho SR, Do QT, Shin HK. Residual strength of damaged ringstiffened cylinders subjected to external hydrostatic pressure. 2017;56:186-205. Available from: https://doi.org/10.1016/j. marstruc.2017.08.005.

20. Do QT, Muttaqie T, Shin HK, Cho SR. Dynamic lateral mass impact on steel stringer-stiffened cylinders. Int J Impact Eng. 2018;116(1):105-126. Available from: https://doi.org/10.1016/ j.ijimpeng.2018.02.007.

21. Do QT, Muttaqie T, Park SH, Shin HK, Cho SR. Ultimate strength of intact and dented steel stringer-stiffened cylinders under hydrostatic pressure. Thin-Walled Struct. 2018;132:442-460. Available from: https://doi.org/10.1016/j.tws.2018.09.010.

22. Do QT, Huynh VV, Vu MT, Tuyen VV, Pham TN. A New Formulation for Predicting the Collision Damage of Steel Stiffened Cylinders Subjected to Dynamic Lateral Mass Impact. Appl Sci. 2020;10(11):3856. Available from: https://doi.org/10.3390/ app10113856.

23. API. Bulletin on Stability Design of Cylindrical Shells, API Bulletin 2U, 3rd ed., Washington. 2004;.

24. Muttaqie T, Do QT, Prabowo AR, Cho SR, Sohn JM . Numerical studies of the failure modes of ring-stiffened cylinders under hydrostatic pressure. Structural Engineering and Mechanics. 2019;70(4):431-443.

25. Cho SR, Frieze PA. Strength formulation for ring-stiffened cylinders under combined axial loading and radial pressure. Journal construction steel research. 1988;9:3-34. Available from: https://doi.org/10.1016/0143-974X(88)90054-5. 